Technical Report No. 32-17I

\title{
A 500-Electrical-Watt Solar Energy Thermionic Conversion System for a Mars Spacecraft
}

\author{
Aruin H. Smith
}

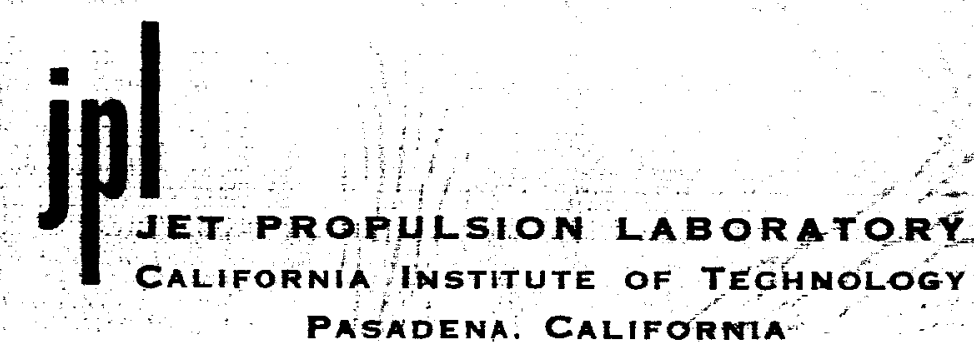

April 15, 1962 
National Aeronautics and Space administration CONTRACT NO. NAS 7-100

Technical Report No. 32-17I

\title{
A 500-Electrical-Watt Solar Energy \\ Thermionic Conversion System for a Mars Spacecraft
}

Aruin H. Smith

OF tolmenten

G.E. Sweetham, Chief

Spacecraft Secondary Power Section

\author{
JET PROPULSION LABORATORY \\ California institute of TECHNOLOGY \\ PASADENA, CALIFORNIA
}

April 15, 1962 
Copyright ${ }^{\odot} 1962$

Jet Propulsion Laboratory

California Institute of Technology 


\title{
CONTENTS
}

\begin{abstract}
Summary . . . . . . . . . . . . . . . . . . . . . . . . 1
Infroduction . . . . . . . . . . . . . . . . . . . . . . . 3

Solar Energy Photovoltaic Conversion . . . . . . . . . . . . . 4

Solar Energy Thermionic Conversion . . . . . . . . . . . . . . . . 6

SET (B) Prototype . . . . . . . . . . . . . . . . . . . . . . . . . . 10

Conclusion . . . . . . . . . . . . . . . . . . . . . . . 12

References . . . . . . . . . . . . . . . . . . . . 13
\end{abstract}

\section{TABLES}

1. Solar energy photovoltaic conversion system . . . . . . . . . . . . . 4

2. Electrical power systems for a Mars spacecraft . . . . . . . . . . . 8

3. Solar concentrator summary . . . . . . . . . . . . . . . . . 10

4. Thermionic diode summary . . . . . . . . . . . . . . . . . 11

5. Summary of experimental thermionic converter characteristics and performance . . . . . . . . . . . . . . . . . . . . 11

\section{FIGURES}

1. Mars spacecraft with 500-watt photovoltaic conversion system . . . . 5

2. Mars spacecraft with SET (A) 500-watt thermionic conversion system . . 7

3. Mars spacecraft with SET (B) thermionic conversion system . . . . . . 9

4. Prototype SET (B) mirror with mock thermionic generator . . . . . . . . 10

5. Thermionic converter $\mathbf{V b}$. . . . . . . . . . . . . . . . . . 11 


\begin{abstract}
The conceptual design of a solar energy thermionic (SET) conversion system suitable for use as the prime source of electrical power for a Mars spacecraft is described. Two designs of such a system are considered. The most promising design, designated SET (A), would employ an individual, 9.5-ft-diameter, rigid, parabolic mirror to intercept, reflect, and concentrate solar energy. A multidiode thermionic generator would convert the concentrated thermalized solar energy into electricity. SET (A) would utilize a 500-electrical-watt thermionic generator incorporating a cavity-type absorber, cesium-vapor-filled thermionic diodes, heat radiators, temperature-controlled cesium reservoirs, and a solar flux control mechanism. An alternate design, designated SET (B), would incorporate a 5 -ft-diameter mirror and a 135-watt thermionic generator. Four such modules would be clustered to provide up to 540 watts of electrical power at Mars (aphelion). The design features of a 135-watt flight prototype, which is currently under active development, are presented. It is concluded that potentially advantageous solar energy thermionic conversion systems are possible, provided that long life and adequate reliability can be achieved.
\end{abstract}

\title{
SUMMARY
}

The importance of minimizing solar collector area in the design of electrical power systems for sophisticated planetary spacecraft is established. The development of more efficient energy-conversion systems is selected as giving the most promise of reducing both weight and collector area. Solar energy thermionic (SET) conversion systems, which are capable of greater overall conversion efficiencies than can be expected from singlejunction silicon photovoltaic cells, may be feasible. Theoretically, thermionic conversion efficiencies greater than $30 \%$ are possible. Thermionic conversion efficiencies greater than $15 \%$ have been achieved experimentally.
The characteristics of the Ranger photovoltaic cell panels are described. It is estimated that a 500 -electricalwatt solar energy photovoltaic conversion system, suitable for use on a 1964 Mars spacecraft, would require a collector area of $105 \mathrm{sq} \mathrm{ft}$ and would weigh approximately $137 \mathrm{lb}$.

Two conceptual 500-electrical-watt solar energy thermionic conversion systems are described. The most promising model, designated SET (A), would employ a rigid, $9.5 \mathrm{ft}$-diameter parabolic mirror to intercept, reflect, and concentrate solar energy. A multidiode thermionic 
generator would convert the concentrated thermalized solar energy into electricity. SET (A) would utilize a 500-electrical-watt thermionic generator which would incorporate a cavity-type absorber, cesium-vapor-filled thermionic diodes, heat radiators, temperature-controlled cesium reservoirs, and a solar flux control mechanism. An alternate model, designated SET (B), would incorporate a 5 -ft-diameter mirror and a 135-watt thermionic generator. Four such modules would be clustered to provide up to 540 watts of electrical power at Mars (aphelion). The design features of a 135-watt flight prototype, currently under active development, are presented. It is concluded that potentially advantageous solar energy thermionic conversion systems are possible, provided that long life and adequate reliability can be achieved. 


\section{INTRODUCTION}

A spacecraft utilizing the Sun's radiant energy as the prime source of electrical power will require approximately $23 / 4$ more collector area in the vicinity of Mars (aphelion) than in Earth space to provide an equivalent power. A collector area capable of supplying 500 electrical watts at the aphelion distance $\left(154.6 \times 10^{6} \mathrm{mi}\right)$ of Mars would provide 1375 watts in Earth space, assuming constant conversion efficiency and continuous sunlight operation. The weight allocated to large collectors deprives the spacecraft of precious pounds which would otherwise be available for scientific and engineering experiments. Also, large collectors impose constraints which complicate the design and integration of such spacecraft subsystems as attitude control, communication antennas, midcourse guidance, and scientific instruments. The importance of minimizing collector area in the design of sophisticated spacecraft is not always appreciated. The collector area of a Sun-oriented flat array can be minimized by reducing the required electrical power and/or increasing the conversion efficiency of the projected area. Collector weight can be reduced by decreasing specific weight (pounds per square foot) and/or collector area. For a fixed power requirement, area-and hence weight-can be reduced by increasing conversion efficiency. If a simultaneous decrease in specific weight can be achieved-and this is more easily accomplished with small collectors-significant weight and area advantages can result.

In the past four years, the thermionic conversion of heat to electricity has attracted the interest of a growing number of researchers and engineers (Ref. 1-4) eager to explore the potential of thermionic energy conversion. Maximum conversion efficiencies ranging from approximately $15 \%$ at an emitter temperature of $1400^{\circ} \mathrm{K}$ to $38 \%$ at an emitter temperature of $2600^{\circ} \mathrm{K}$ have been calculated by Rasor (Ref. 5). Houston (Ref. 6) has concluded that conversion efficiencies of $30 \%$ or more are possible. Experimentally, Rasor (Ref. 7) has reported a measured efficiency in excess of $17 \%$ for a laboratory model cesium-vapor thermionic converter. Thermo Electron Engineering Corporation ${ }^{1}$ has manufactured a 200watt cesium thermionic converter of cylindical geometry exhibiting a reported measured efficiency of $13 \%$ (Ref. 8). Jensen has reported (Ref. 9) that efficiencies ranging from approximately $10 \%$ at an emitter temperature of $1300^{\circ} \mathrm{C}$ to $15 \%$ at $1500^{\circ} \mathrm{C}$ have been calculated from the measured performance of production-type vapor thermionic converters. The operational life of cesium thermionic converters tested to date has been limited to tens of hours, except for certain less efficient devices which have operated for a few hundred hours, usually with a performance which decreased with time.

Despite the rather limited life demonstrated to date, the high theoretical efficiencies and encouraging experimental performance obtained by some researchers have prompted engineers in the spacecraft electrical power field to consider the possible merits of solar energy thermionic (SET) conversion systems. Since overall conversion efficiencies greater than can be expected from single-junction silicon photovoltaic cells may be possible with carefully engineered SET systems, it appeared desirable to investigate such power systems for one of the Jet Propulsion Laboratory's proposed Mars spacecraft. During the latter part of 1960 , preliminary design analysis and configuration studies were initiated.

In this paper, two models of a 500-electrical-watt SET system are compared with an advanced photovoltaic conversion system. Design features are presented of a 135-electrical-watt SET system, which is currently being developed at Electro-Optical Systems, Inc., ${ }^{2}$ under contract to JPL.

\footnotetext{
1 Waltham, Mass.

2 Pasadena, Calif
} 


\section{SOLAR ENERGY PHOTOVOLTAIC CONVERSION}

Since the Earth-to-Mars transit time will probably be in excess of 200 days, long-duration power sources will be required. The solar energy photovoltaic conversion system is currently the only type which has demonstrated a capability of operating in the space environment for sufficiently long periods of time to be considered for a Mars mission. In this study we shall assume that Ranger photovoltaic cell panels are representative of current technology. Table 1 presents the design features of the photovoltaic cell panels which supply electrical power to the Ranger lunar spacecraft and the estimated performance of a 500-watt photovoltaic conversion system which could be available for launching in early 1964 . A conceptual Mars spacecraft based on such a system is shown in Fig. 1.

Several factors affect the design of photovoltaic conversion systems. One of the more critical is the accurate determination of space efficiency from measurements performed in simulated sunlight or sunlight at the Earth's surface. The photovoltaic cell is not equally responsive to electromagnetic radiation of all wavelengths. Until recently, manufacturers of photovoltaic cells specified conversion efficiencies as measured in tungsten light at a cell temperature of $25^{\circ} \mathrm{C}$. The efficiency of a 1 - by $2-\mathrm{cm}$ cell was based on the $1.8-\mathrm{cm}^{2}$ active area. Light sources which more closely simulate the solar irradiance in space are now available, and cell manufacturers are beginning to specify an efficiency based on space. The accuracy of efficiencies measured with the new simulators has not been adequately determined. The efficiency of the projected area of a Sunoriented flat array may be substantially less than the efficiency based on active cell area if losses resulting from absorption and reflection in cover glass and cover glass adhesive, from mismatching of series-parallelconnected cells, and from an area utilization less than unity are not minimized. The relationship between cell efficiency and the efficiency of the projected panel area is shown in Table 1.

The life and reliability of photovoltaic conversion systems are considered excellent. The Van Allen radiation belts do not constitute a particular hazard to photovoltaic cell performance on a planetary spacecraft, since the belts are left behind soon after launch. However, solar protons, cosmic rays, solar ultraviolet and $\mathrm{X}$ radi- ation, meteoroids and micrometeorites may adversely affect photovoltaic panel performance. Based on current knowledge of the space environment and solar cell sensitivity to such environment, it is considered possible that the damage resulting from a 225-day transit from Earth to Mars may degrade conversion efficiency by as much as $25 \%$. Table 1 does not contain a contingency for the deleterious effects of the space environment. If a $25 \%$ degradation were to be incurred, the electrical power available at Mars would be only 375 watts instead of the indicated 500. The design of a photovoltaic conversion system is further complicated by the variation in solar flux encountered during transit from Earth to Mars. The diminution in solar flux will cause a corresponding decrease in solar cell temperature and electrical power. Photovoltaic conversion system voltage will increase as a result of the decrease in solar cell temperature. A 500-watt system at Mars would deliver approximately 1150 watts near Earth. As a result, part of the extra power may have to be dissipated in a shunting load to limit the maximum source voltage. The photovoltaic conversion system described will provide the basis for comparing the relative merits of competing solar energy thermionic conversion systems.

Table 1. Solar energy photovoltaic conversion system

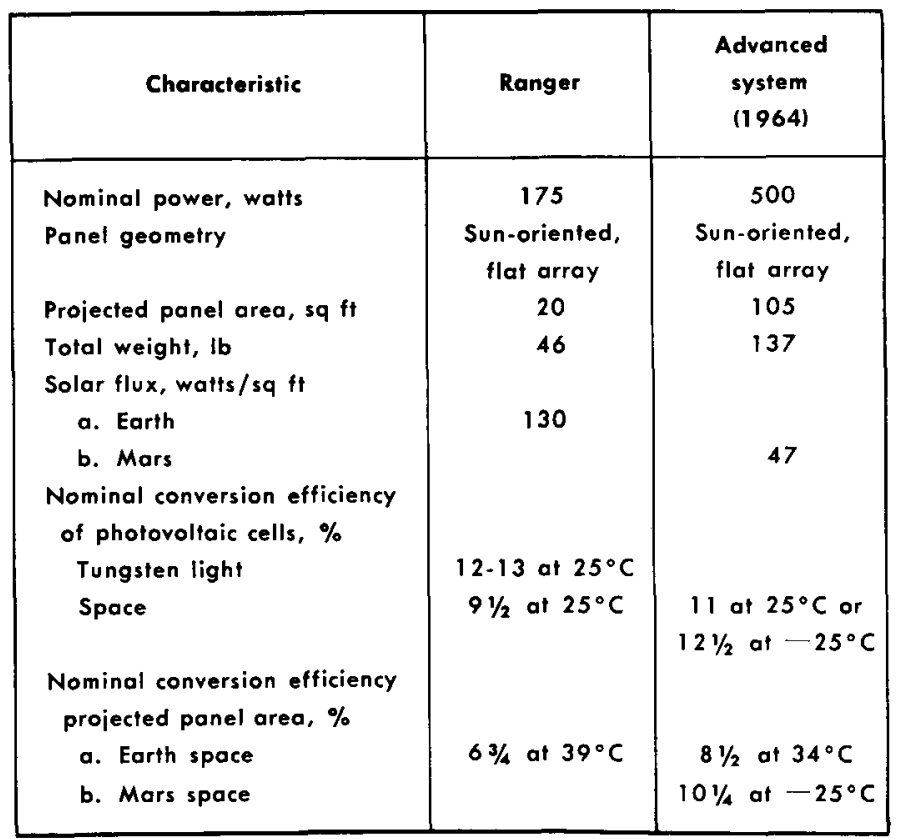




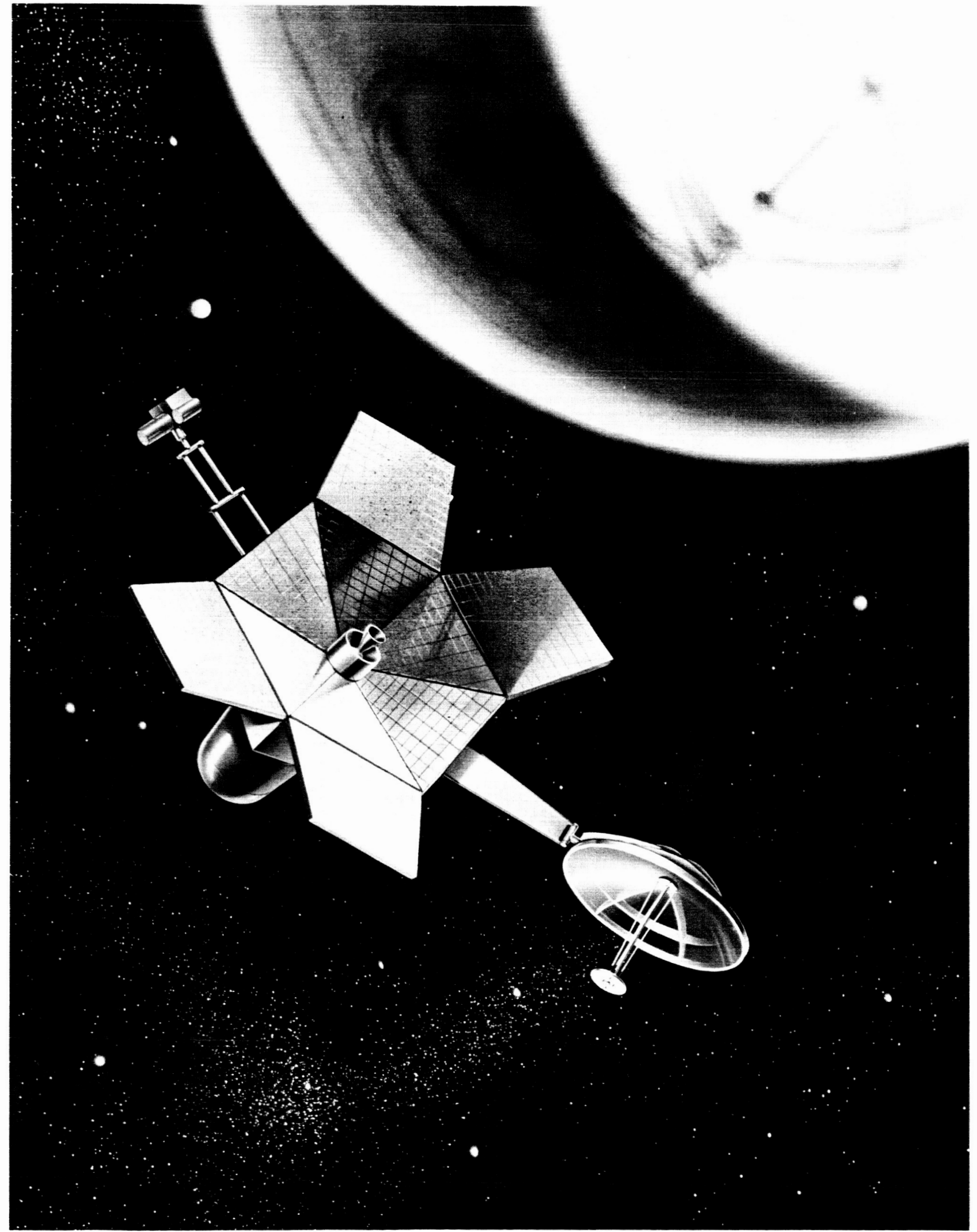

Fig. 1. Mars spacecraft with 500-watt photovoltaic conversion system 


\section{SOLAR ENERGY THERMIONIC CONVERSION}

Five conceptual designs of a SET system have been studied. These designs are compatible with the AtlasCentaur class of launch vehicle and suitable for use as the prime source of electrical power for a Mars spacecraft requiring a nominal output of 500 watts throughout transit from Earth to Mars. They can be described as follows:

(A) One 9.5-ft-diameter concentrator (mirror) with a multidiode thermionic generator.

(B) Four 5-ft-diameter solar concentrators with multidiode thermionic generators.

(C) Six 4-ft-diameter concentrators with a monodiode generator.

(D) Eight 3-ft-diameter solar concentrators with monodiode thermionic generators.

(E) Two 6.5-ft-diameter solar concentrates with multidiode thermionic generators.

All configurations except SET (A) and SET (B) were rejected early in the design study. SET (A), which incorporates a single, rigid, 9.5-ft-diameter solar concentrator and a multidiode thermionic generator is considered the most promising. A conceptual Mars spacecraft based on such a system is shown in Fig. 2. The 9.5-ftdiameter solar concentrator is centrally mounted and, when Sun-oriented, shadows the capsule and instrument packages. A parabolic high-gain Earth antenna is attached at the lower right. At the upper left is a scientific-instrument platform oriented in the direction of the target planet. Three midcourse motors are shown exterior to the toroidal structure. (A more detailed description of this spacecraft can be found in Ref. 10.)

SET (A) would utilize a 500-electrical-watt thermionic generator incorporating a cavity-type absorber, cesium-vapor-filled thermionic diodes, heat radiators, temperature-controlled cesium reservoirs, and a solar flux control mechanism. The thermionic generator is supported at the focal plane by three legs hinged at the periphery of the mirror. The generator would be stowed within the parabolic shell at a point near the center of the mirror during launch. Once in space, it would be released and positioned at the focal point. In this design the third leg would telescope to facilitate generator actuation. The thin, parabolic mirror shell is attached only to the toroidal structure. The superstructure supporting the instrument packages and landing capsule is attached to the toroidal structure at three points.

It should be emphasized that the design is conceptual; engineering details are purposely omitted. In many cases, details have not been established; those shown are subject to revision. Thermionic generator, antenna, and mirror attachments are typical examples, as are the three midcourse motors shown exterior to the toroidal structure. These positions cannot be occupied during launch since they would exceed the shroud diameter. The SET (A) design features are summarized in Table 2.

It is possible to anticipate many problem areas which will require attention in the development of solar energy thermionic conversion systems. The following are perhaps the most critical, but not necessarily in the order listed:

1. Thermionic generator mechanical design. The attainment of a sound mechanical design which minimizes all extraneous heat losses may prove difficult.

2. Cesium reservoir temperature control. Experimental data (Ref. 7,11 ) indicate that a $1^{\circ} \mathrm{C}$ change from optimum cesium reservior temperature will result in a 1 to $2 \%$ decrease in the electrical power output. Since the cesium reservoir temperature may have an optimum value near $600^{\circ} \mathbf{K}$, an error of only $1 \%$ will result in a 6 to $12 \%$ decrease in output power. This is extremely critical, and it is doubtful whether the necessary control can be achieved and maintained during prolonged space operation. The cesium, as utilized in the thermionic converters considered here, functions to modify both emitter and collector work function as well as to provide space charge neutralization. Separating these functions so that cesium provides only space charge neutralization should relax the cesium reservoir temperature-control requirement. It appears that substantial relaxation of this requirement is necessary before reliable space operation is possible.

3. Cavity and emitter temperature control. The cavity temperature must be controlled during startup to prevent excessive evaporation or melting of components employed in the thermionic generator. This 


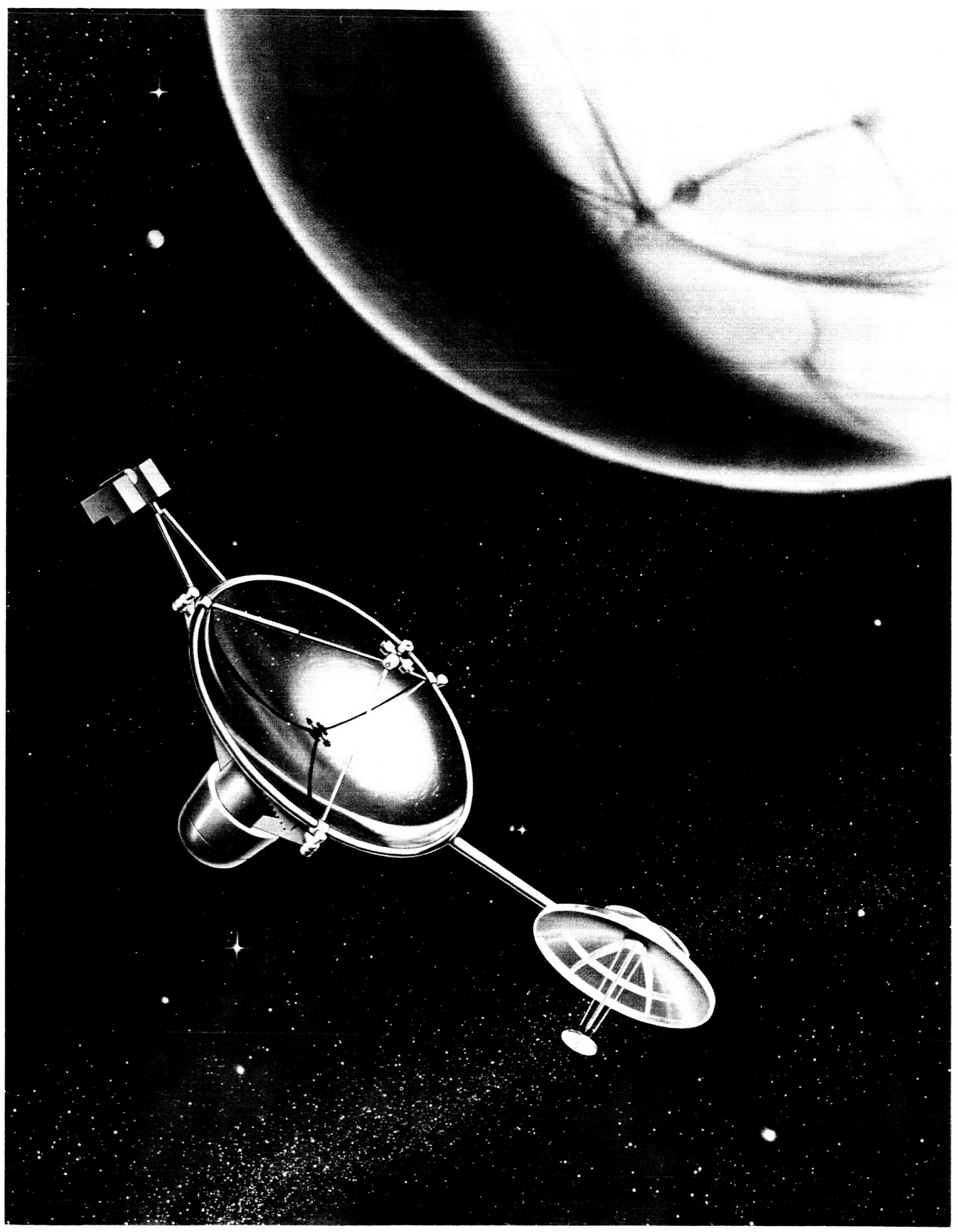

Fig. 2. Mars spacecraft with SET (A) 500-watt thermionic conversion system 
Table 2. Electrical power systems for a Mars spacecraft

\begin{tabular}{|c|c|c|c|}
\hline \multirow{2}{*}{ Characteristic } & \multicolumn{2}{|c|}{ Thermionic conversion } & \multirow{2}{*}{$\begin{array}{c}\text { Photovoltaic } \\
\text { conversion } \\
(1964)\end{array}$} \\
\hline & Set (A) & Set (B) & \\
\hline Projected area, sq ft & 71 & 78 & 105 \\
\hline Total weight $t^{3}$, Ib & $\begin{array}{c}\text { less than } \\
100\end{array}$ & 100 & 137 \\
\hline $\begin{array}{l}\text { Nominal efficiency at } \\
\text { Mars, } \%\end{array}$ & 15 & $14^{b}$ & $10 \frac{1}{4}$ \\
\hline $\begin{array}{l}\text { Minimum service life, } \\
\text { days in space }\end{array}$ & 250 & 250 & 250 \\
\hline Relative reliability rating & 2 & 3 & 1 \\
\hline
\end{tabular}

can be classified as a safety control and can be accomplished in a relatively gross manner. If voltage and power regulation are to be achieved, the emitter temperature must also have vernier control.

4. Solar flux control. If the conversion system is to be utilized in the electrical power system for a planetary spacecraft, provisions for controlling the net solar flux transferred to the cavity must be provided. One control mechanism which could adjust for the changing solar flux, function as a safety control during startup, and provide vernier emittertemperature control appears desirable. This is a second factor which may critically influence system reliability, although it may not impose as severe a requirement as cesium reservoir temperature control.

5. Sun orientation. Misorientation of less than 1 minute of arc is desirable; however, 6 minutes can be accommodated if a decrease in mirror absorber efficiency can be permitted.

6. Mechanical integrity during exposure to the ground test, launch, and space environment.

An alternate model, designated SET (B), of the solar energy thermionic conversion system has been studied. The SET (B) design features are summarized in Table 2. A Mars spacecraft incorporating such a design is shown in Fig. 3. The SET (B) system consists of four modules, each incorporating a 5-ft-diameter mirror and a 135-watt multidiode thermionic generator. The extent to which the power system influences spacecraft design can be seen by comparing Fig. 2 and 3. The antenna, scientific instrument platform, and capsule are common to both configurations. However, the three midcourse motors have been replaced with a single motor. The necessity of deploying mirrors and thermionic generators has complicated the spacecraft design, possibly with a sacrifice in reliability. An early prototype of one module of the SET (B) is under active development. 


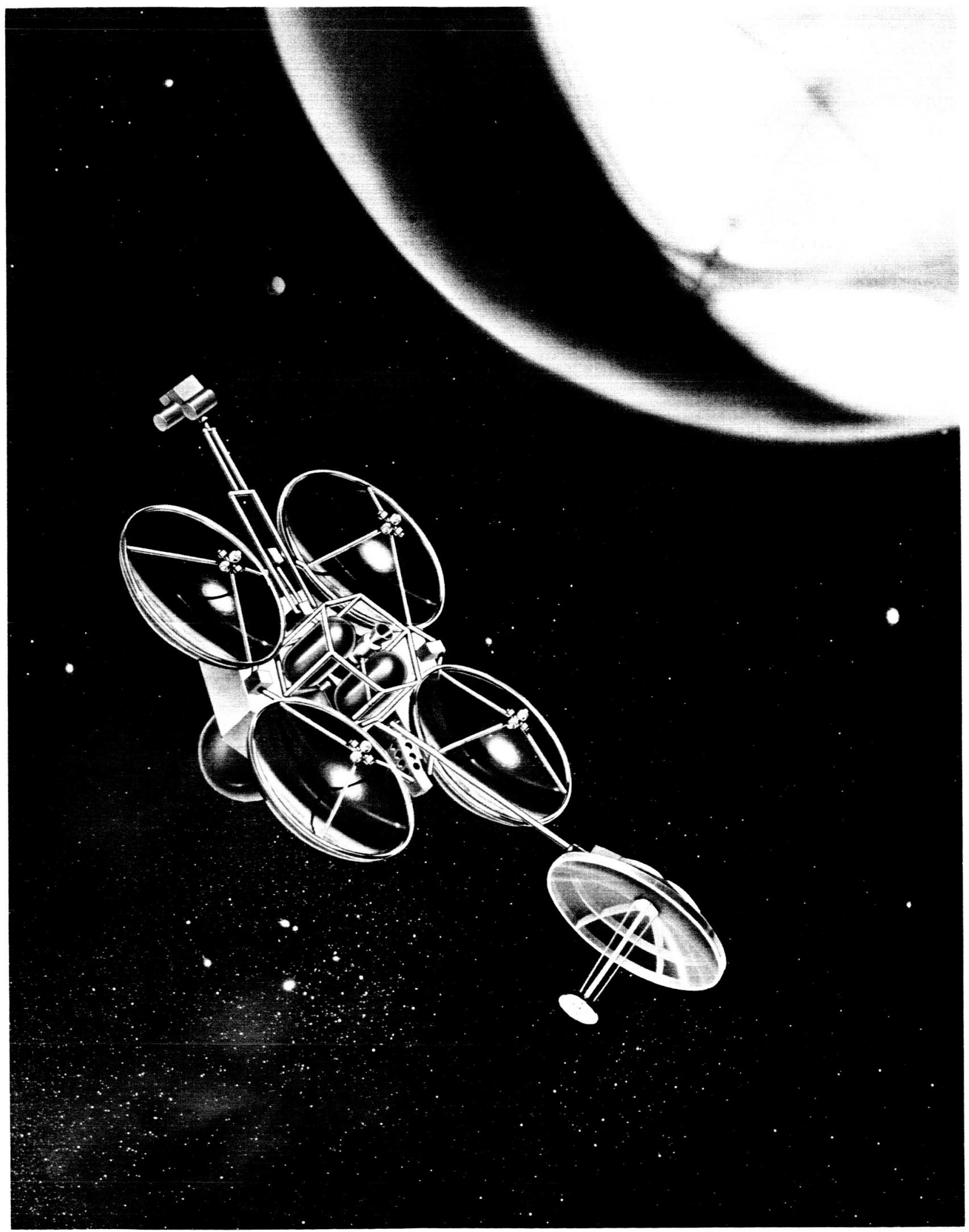

Fig. 3. Mars spacecraft with SET (B) thermionic conversion system 


\section{SET (B) PROTOTYPE}

On May 22,1961, Electro-Optical Systems, Inc., under contract to JPL, initiated development of a 135-electricalwatt solar energy thermionic conversion system. The major subcontractor, Thermo Electron Engineering Corporation, is responsible for the thermionic generator development. The SET (B) prototype will incorporate a 5-ft-diameter parabolic concentrator manufactured at Electro-Optical Systems and utilizing a nickel electroforming process developed under ABMA and NASA contracts. The first surface of the parabolic concentrator (mirror) will be covered with a thin coat of vapordeposited aluminum to obtain a high specular reflectance. During space operation, the optical axis of the mirror would be directed toward the Sun, and the mirror would collect and reflect a concentrated beam of solar energy through the aperture of a cavity-type absorber. The cavity absorber, which is approximately spherical, is actually an integral part of the thermionic generator and functions to convert the concentrated radiant energy into heat energy, which is supplied to the emitters of five thermionic converters. A summary of the more important characteristics selected as a result of the analytical design and submitted to JPL in the SET Preliminary Design Report (Ref. 11) is given in Table 3.

Four early prototypes of the SET (B) concentrator have been fabricated to verify the proposed design and manufacturing techniques. Electro-Optical Systems has reported measured concentrator efficiencies of 62 and $71 \%$ for prototypes 3 and 4, respectively. These efficiencies were obtained with a 0.5 -in-diameter aperture and a corresponding geometric concentration ratio of over 14,000. The design requirement, as shown in Table 3, is $88.9 \%$. A SET (B) concentrator and mock thermionic generator are shown in Fig. 4.

The thermionic generator incorporates a cavity-type absorber, a molybdenum housing, five temperature-controlled cesium reservoirs, an emitter temperature sensor, a collector temperature sensor, and five planar-geometry cesium-vapor-filled thermionic diodes arranged to form five faces of a cube. Concentrated solar energy enters the cavity absorber through a 0.5-in.-diameter aperture in the sixth face of the cube. The generator as presently designed would produce an electrical power of 135 watts, operate with an efficiency of $20.8 \%$, weigh slightly less than $3.4 \mathrm{lb}$, and have a service life of one year.

\section{Table 3. Solar concentrator design requirements}

Diameter of useful reflecting surfaces, in. .............6.4 Overall diameter, including torus rim support, in. ..........66

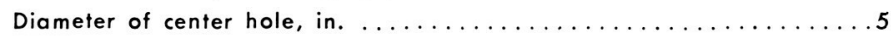
Useful projected area of mirror, less obstructions, sq $f 1 \ldots \ldots \ldots 19.25$ Rim angle, useful reflecting surface, deg............62 Concentration ratio (average over 0.5 -in. cavity aperture) ....13,000 Concentration efficiency, energy entering cavity/energy

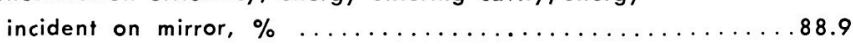

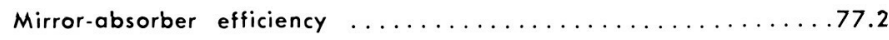
Type of skin structure.............rim-supported paraboloidal shell

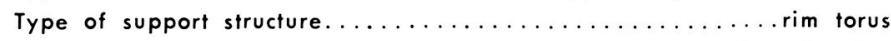
Fabrication technique (skin and torus)............electroforming

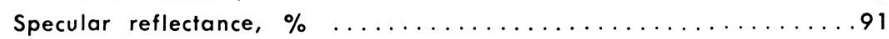
Angular mirror surface inaccuracy, $1 \sigma, \min$ of arc............ Radius of circle of confusion, $3 \sigma$, collimated incident light, in...... 0.1

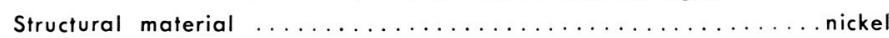

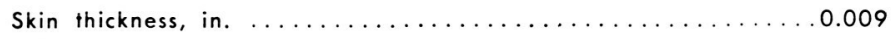

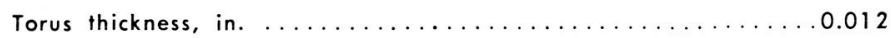

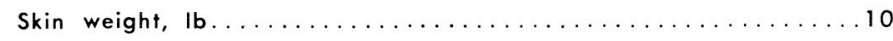

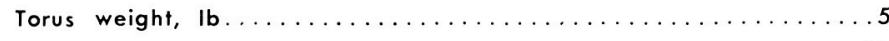

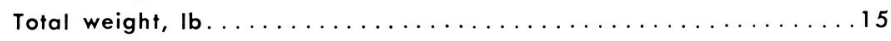

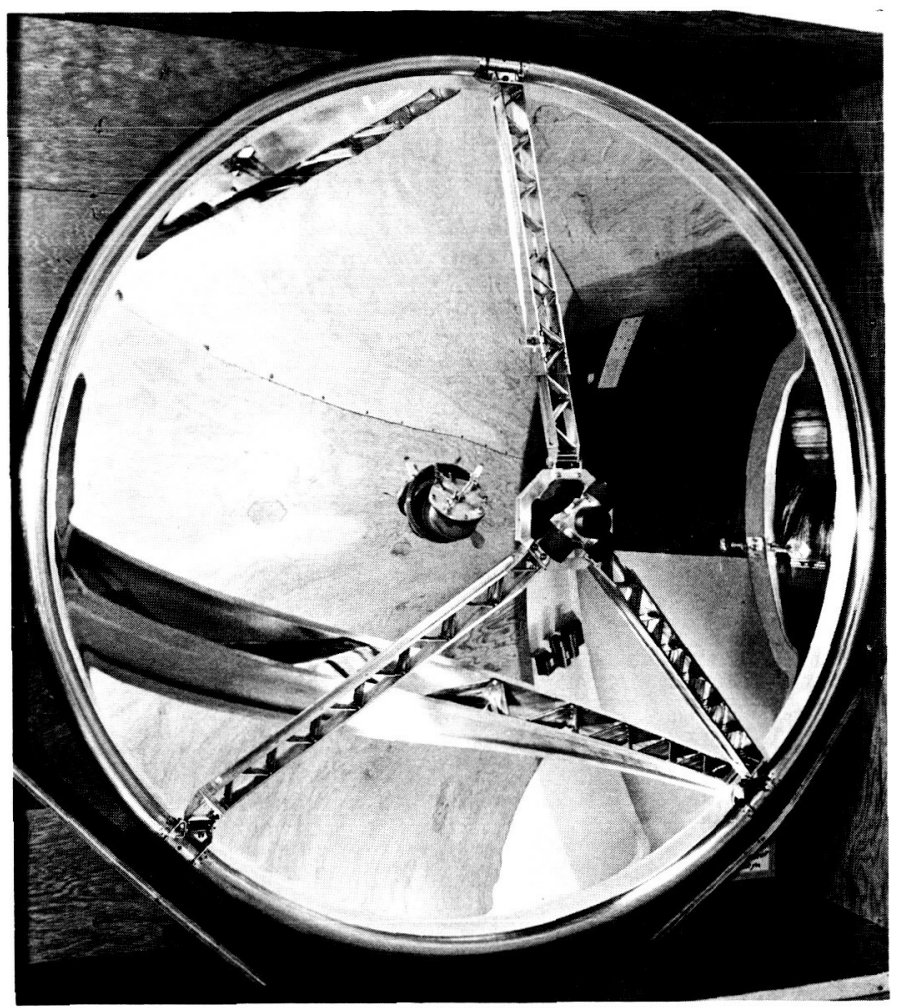

Fig. 4. Prototype SET (B) mirror with mock thermionic generator 
The basic component of the generator is the thermionic diode. A summary of the more important design features (Ref. 11) of the thermionic diode is given in Table 4 . The design values specified were selected by Thermo Electron Engineering Corporation and are based on a required thermionic generator efficiency of $20.8 \%$.

\section{Table 4. Thermionic diode design requirements}

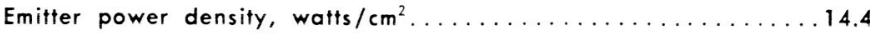
Emitter.temperature, ${ }^{\circ} \mathrm{K} \ldots \ldots \ldots \ldots \ldots \ldots \ldots . \ldots \ldots \ldots$

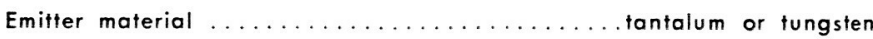
Emitter-collector geometry .................... planar

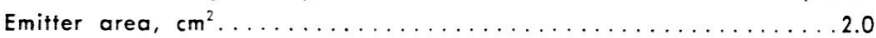
Interelectrode spacing, in. ............... approximately 0.002

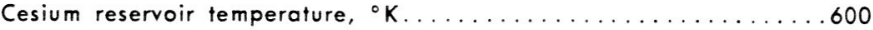

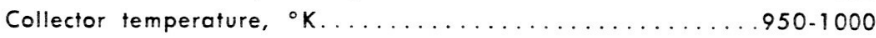
Collector material ................tantalum or molybdenum

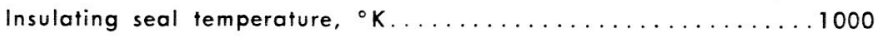
Insulating seal construction..........ceramic $\left(A L_{2} \mathrm{O}_{3}\right)$ brazed to niobium

Characteristics and performance of the thermionic converter fabricated and tested in this program through October 20, 1961, are summarized in Table 5. Thermionic converter $\mathrm{Vb}$ is shown in Fig. 5 .

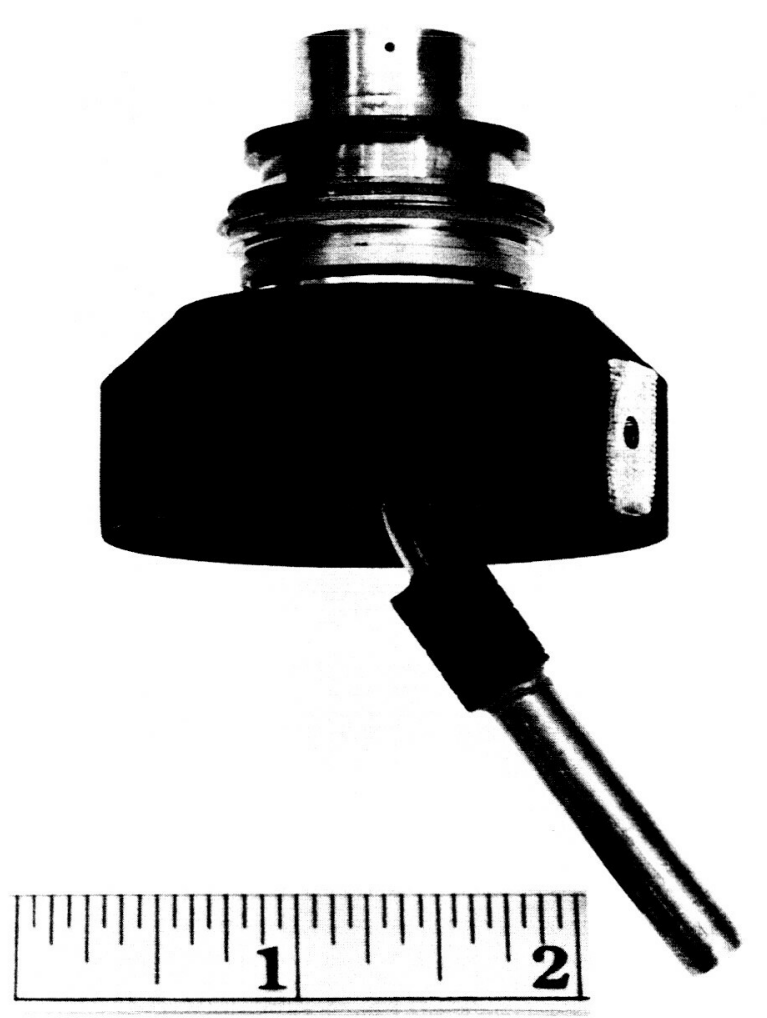

Fig. 5. Thermionic converter Vb

Table 5. Summary of experimental thermionic converter characteristics and performance

\begin{tabular}{|c|c|c|c|c|c|c|c|}
\hline Converter & $\begin{array}{c}\text { Electrical } \\
\text { output } \\
\text { at } \\
1.00 \mathrm{v}, \\
w / \mathrm{cm}^{2}\end{array}$ & $\begin{array}{c}\text { Emitter } \\
\text { temperature, } \\
{ }^{\circ} \mathrm{K}\end{array}$ & $\begin{array}{l}\text { Emitter } \\
\text { material }\end{array}$ & $\begin{array}{l}\text { Collector } \\
\text { material }\end{array}$ & $\begin{array}{l}\text { Optimum } \\
\text { cesium } \\
\text { temper- } \\
\text { ature, } \\
{ }^{\circ} \mathrm{K}\end{array}$ & $\begin{array}{l}\text { Calculated } \\
\text { inter- } \\
\text { electrode } \\
\text { spacing, } \\
\text { mil }\end{array}$ & $\begin{array}{c}\text { Operating } \\
\text { time before } \\
\text { shutdown } \\
\text { or failure, } \\
\text { hr }\end{array}$ \\
\hline IIb & 12 & 2000 & W & Mo & not measured & 1.61 & 18 \\
\hline IIIa & 9.5 & 2000 & W & $\mathrm{Ta}$ & 659 & 2.09 & 97.5 \\
\hline $\mathrm{IVb}$ & 9.1 & 2000 & Ta & Mo & 647 & 2.09 & 165 \\
\hline IVe & 5.0 & $\approx 2000$ & $\mathrm{Ta}$ & Mo & 658 & 2.09 & 322 \\
\hline $\mathrm{Va}$ & 6.0 & 1980 & $\mathrm{Ta}$ & $\mathrm{Ta}$ & 617 & 2.3 & 850 \\
\hline $\mathrm{Vb}$ & 5.5 & 1980 & $\mathrm{Ta}$ & $\mathrm{Ta}$ & 601 & 2.3 & 80 \\
\hline$V_{c}$ & 6.0 & 1980 & $\mathrm{Ta}$ & Ta & 617 & 2.3 & 269 \\
\hline$V d$ & 5.5 & 1980 & Ta & Ta & 640 & 2.3 & 421 \\
\hline $\mathrm{Te}-1$ & 5.5 & 1980 & Ta & $\mathrm{Ta}$ & 640 & 2.3 & 950 \\
\hline Te-2 & - & - & $\mathrm{Ta}$ & Ta & - & 2.3 & 220 \\
\hline
\end{tabular}




\section{CONCLUSION}

Potentially advantageous SET conversion systems appear feasible, provided that long life and adequate reliability can be achieved. The feasibility of the conceptual 500-electrical-watt SET systems described has not been established. It is the author's contention that SET con- version systems must provide significant advantages in terms of reduced weight, less collector area, and lower cost to offset certain apparent disadvantages; and unless such performance can be achieved, SET systems will not find application in sophisticated planetary spacecraft.

\section{ACKNOWLEDGMENT}

The author wishes to acknowledge the assistance of J. S. Hasbrouck and R. W. Crismore of JPL, Walter Menetrey of Electro-Optical Systems, Inc., and Pierre Brosens of Thermo Electron Engineering Corporation.

\section{REFERENCES}

1. Casey, E. F., and Street, G., Jr., "A Thermionic Power Supply Using Solar Heat for Space Application," paper (59-904) presented at AIEE Summer General Meeting, June 1959.

2. Oman, H., and Street, G., Jr., "Experimental Solar Thermionic Converter for Space Use," paper presented at AlEE Pacific General Meeting, San Diego, August, 1960.

3. Purdy, D. L., "Solar Thermionic Electric Power System," ARS paper 1311-60, 1960.

4. Henderson, R. E., and Dresser, D. L., "Solar Thermionic Space Systems," SAE paper 350C, National Aeronautic Meeting, New York, 1961.

5. Rasor, N. S., "Parametric Optimization of the Emission-Limited Thermionic Converter," ARS paper 1283-60, 1960.

6. Houston, J. M., "Theoretical Efficiency of the Thermionic Energy Converter," J. Appl. Phys., Vol. 30, no. 4, 1959.

7. Rasor, N. S., "Experimental Research on the Cesium Thermionic Converter," IAS paper 61-72, 1961.

8. Aviation Week, September 4, 1961, p. 61

9. Baum, E. A., and Jensen, A. O., "Thermionic Converter Design Status and Forecast," Proceedings of the Fifteenth Annual Power Sources Conference, 1961.

10. Gates, C. R., "A Description of a Mars Spacecraft with a Landing Capsule," IASARS paper 61-180-874, National Joint Meeting, June 13-16, Los Angeles, 1961.

11. Preliminary Design Report, Solar Energy Thermionic Conversion System, prepared by Electro-Optical Systems, Inc., Pasadena, Calif., and Thermo Electron Engineering Corp., Waltham, Mass., June 1961. 